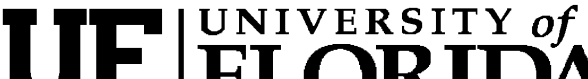 FLORIDA \\ IFAS Extension
}

\section{Good Agricultural Practices (GAPs) ${ }^{1}$}

\section{Raymond Reyes and Edward Evans ${ }^{2}$ \\ Introduction}

Good agricultural practices (GAPs) at the farm level involve multi-faceted efforts at ensuring that foods are safe for human consumption. Food safety has become a serious issue in our society because of pathogens and food contamination. The United States Department of Agriculture (USDA) and the United States Food and Drug Administration (FDA) are responsible for recalling contaminated foods, but because food can become contaminated at all levels of the food production system, it is essential to keep food safe through GAPs.

Failure to institute a GAP program allows the risk of contaminated food products in the production process. Well-managed GAPs have proven effective in reducing the risks of food contamination in agricultural production (University of Maryland 2002). This article provides a brief overview of the concept of GAPs and highlights some of the potential consequences of not instituting GAP guidelines into a farm's operation.

\section{Good Agricultural Practices (GAPs)}

There are a variety of GAPs that can be instituted at the farm level. This document identifies two GAP program types with general concepts, the specific components of which are necessarily determined by the organization using them.

1. GAP programs help farmers self-audit their operations of producing, processing, and transporting products of plant and animal origin to safeguard food products, the environment, and the people who consume and produce the products. Providing safe foods and promoting safety for humans and the environment include all the steps in the production chain from farm to consumer (Ag-Network-Chile 2008)

2. GAPs are a set of recommendations to improve the quality and safety of agricultural products. These general guidelines can be used in any production system. GAPs focus on four primary components of production and processing: soil, water, hands, and surfaces. A GAP document specifically details the farm components that are being targeted for a GAP program (Ellis, et al. 2004).

\section{Examples of GAP Programs}

There are many public and private organizations that offer GAP programs. This includes universities,

1. This is EDIS document FE714, a publication of the Food and Resource Economics Department, Florida Cooperative Extension Service, Institute of Food and Agricultural Sciences, University of Florida, Gainesville, FL. Published October 2008. Please visit the EDIS website at http://edis.ifas.ufl.edu.

2. Raymond Reyes, graduate student, and Edward Evans, assistant professor, Food and Resource Economics Department, Tropical Research and Education Center, Homestead, FL, Florida Cooperative Extension Service, Institute of Food and Agricultural Sciences, University of Florida, Gainesville, FL. 
especially those that work in conjunction with local extension services. These organizations assess how well a farm's current production practices meet GAP standards and government standards (the Food and Drug Administration, or FDA).

For example, the University of California-Davis (UCCE) website is an excellent resource for GAP programs. The UCCE website offers an extensive list of programs for farmers, including topics such as Good Agricultural Practices:

A Self-Audit for Growers and Handlers at http://ucce.ucdavis.edu/files/filelibrary/5453/4362.pdf with topics organized in a question-and-answer format that allows readers to answer the questions and to follow the helpful tips for improvement provided with each answer. Each question has a "yes" or "no" answer, followed by a detailed explanation. Many of the questions include a figure or an image to provide visual aids of the explanations (University of California-Davis 2008).

Another example of a university with GAP information and guidelines is the University of Maryland (UM). The Joint Institute for Food Safety and Applied Nutrition (JIFSAN), a multidisciplinary research and education program jointly administered by the FDA and UM, published Improving the Safety and Quality of Fresh Fruit and Vegetables: A Training Manual for Trainers as well as the JIFSAN Good Aquacultural Practices Manual. Used in trainings nationwide, the manuals provide valuable information on GAPs/GAqPs, food laws and regulations, and food safety and quality assurance issues in clear and accessible terms and are available online at http://www.jifsan.umd.edu/gaps.html and http://www.jifsan.umd.edu/gaqps_man.html, respectively. While our focus here is primarily on agriculture rather than aquaculture, we would be remiss in not mentioning both of these resources-each discusses the potential risks associated with specific areas of farm production, explains the importance of preventing contamination, and provides farm procedure guidelines for farmers to use in their own farm systems (University of Maryland 2002 and 2007).

The Florida Department of Agriculture and Consumer Services (FDACS) provides a helpful guide for tomato good agricultural practices (T-GAP) and tomato best management practices (T-BMP) on its website at http://www.doacs.state.fl.us/fs/ TomatoBestPractices.pdf. This manual is divided into two main sections: tomato production and tomato harvesting/post-harvesting activities. The manual contains recommendations to help reduce the risk of contamining tomatoes, such as fences to keep out animals, safe pesticides, and good drainage (FDACS).

\section{GAP Food Safety Plans}

Contamination of farm goods affects both consumers and agricultural producers. Table 1 provides information from the USDA Economic Research Service (ERS) about pathogen-induced foodborne illnesses in the United States from all sources (domestic and imported), including the number of cases and the estimated costs involved.

Developing a food safety plan is very important in reducing the risks that may jeopardize food product safety (Ellis, et al. 2004). For example, the Iowa State University Extension recommends the following five steps to creating a plan: list, identify, monitor, modify, and document. Following these five steps, farmers should list the actions taken all the way through the production chain, identify points in the process where the risk of contamination may be an issue, monitor the potential areas of risk, modify the procedures if necessary, and document or record any changes made to normal procedures.

\section{Possible Consequences without GAPs}

Not instituting GAP guidelines into a farm's operation allows contamination risks to be present. Therefore, GAP guidelines should be a priority for all farmers since they benefit both consumers and producers. GAPs can help trace contaminated foods back to the "handlers and growers" responsible for unsafe agricultural products (University of California-Davis 2008).

An important aspect of each farm operation is the transportation of agricultural products because of the risk of contamination during transportation and distribution (University of California-Davis 2008). 
Preventing contamination at all possible sources on the farm and during transportation and distribution is critical because of the impact on both consumers and producers.

Marketing contaminated food products has very serious consequences. According to a study by the University of Maryland (2002), foodborne illness is a health hazard and can cause death. It has been estimated that, each year, in developing countries, over 1,500 million children under the age of five years suffer from diarrhea and over 3 million die as a result. Costs related to foodborne illness include healthcare costs, research costs to investigate and control outbreaks, lost revenues to businesses, and legal costs for related litigations.

\section{Concluding Remarks}

GAP guidelines are necessary for all agricultural operations. Self audits should be conducted on a regular basis to determine whether a farm meets individual and government GAP standards. Food safety programs should be instituted to prevent foodborne illnesses and food contamination throughout the whole production process from farm to consumers.

\section{Resources}

Some good resources include programs at:

- Cornell University, http://www.gaps.cornell.edu/ indexhighspeed.html

- Rutgers University, http://www.njaes.rutgers.edu/pubs/downloadfree.asp?strPubID=FS146

- University of Florida, http:/postharvest.ifas.ufl.edu

- University of Rhode Island, http://www.uri.edu/ce/ceec/food/grow.html

- University of Connecticut, http://www.hort.uconn.edu/ipm/foodsafety/ $\underline{\text { toc.htm }}$
-U.S. FDA, http://www.cfsan.fda.gov/ dms/prodguid.html

- FAO, http://www.fao.org/AG/AGP/AGPC/doc/themes/ $\underline{5 \mathrm{~g} \cdot \mathrm{html}}$

\section{References}

Ag-Network-Chile. Good agricultural \& good manufacturing practices. Agricultural Office, Embassy of Chile, Washington, D.C. http://www.ag-network-chile.net/ GAP(s)\%20\&\%20GMP(s).htm

Ellis, Jason, et. al. 2004. On-farm food safety: Guide to good agricultural practices (GAPs). University Extension, Iowa State University, Ames, IA (October).

http://www.extension.iastate.edu/Publications/ PM1974A.pdf

FDACS. Tomato best practices manual. Florida Department of Agriculture and Consumer Services, Tallahassee, FL. http://www.doacs.state.fl.us/fs/ TomatoBestPractices.pdf.

JIFSAN. 2002. Improving the safety and quality of fresh fruit and vegetables. Joint Institute for Food Safety and Applied Nutrition (JIFSAN), University of Maryland, College Park, MD. http://www.jifsan.umd.edu/gaps.html

JIFSAN. 2007. JIFSAN Good aquaculture practices (GAqPS), Joint Institute for Food Safety and Applied Nutrition, University of Maryland, College Park, MD. http://www.jifsan.umd.edu/gaqps_man.html

University of California-Davis. Good agricultural practices: A self-audit for growers and handlers. University of California Cooperative Extension (UCCE), University of California, Davis, CA.

http://ucce.ucdavis.edu/files/filelibrary/5453/4362.pdf

USDA Economic Research Service. Foodborne illness cost calculator. http://www.ers.usda.gov/Data/FoodborneIllness 
Table 1. Foodborne illnesses: number of cases and estimated costs.

\begin{tabular}{|lcc|}
\hline \hline Pathogen & CDC Estimates of Cases & ERS Cost Estimates \\
\hline Campylobacter (foodborne sources) & (per annum) & (2006 U.S. dollars) \\
Salmonella (all sources) & $2,000,000$ & \\
Shig toxin-producing E. coli 0157 (STEC & $1,397,187$ & $\$ 2,467,322,866$ \\
$0157)$ (all sources) & 73,480 & $\$ 445,857,703$ \\
Non-0157 shiga toxin-producing E. coli & 31,229 & \\
(non-STEC 0157) (all sources) & & \\
Listeria (all sources) & 2,797 \\
\hline Source: United States Department of Agriculture, Economic Research Service (USDA/ERS).
\end{tabular}

